\title{
橔 \\ On-campus mine surveying practicals: their contribution in training mining engineering students in an open distance learning context
}

\author{
by F.M. Lugoma*
}

\section{Synopsis}

The University of South Africa (UNISA) is the only South African university offering mine surveying by open distance learning (ODL). Initially intended to service mining engineering practitioners in search of formal training, the university has seen a growing enrolment of private students. Because this cohort of students has had little contact with the mining environment, there is a need to supplement the theoretical training by ODL with practical sessions on campus.

In order to investigate this concern, historical data pertaining to the performance of students over the last five years was collected. Six mine surveying modules forming part of the national diplomas in Mining Engineering and in Mine Surveying offered at UNISA were considered: Mine Survey II and III, Mine Valuation II and III (Mine Surveyors subjects), and Mine Survey and Valuation II and III (Mine Engineering subjects).

A roster was then designed for mine surveying practicals for implementation over one year, with students' attendance being optional. The students who accepted the invitation were monitored for the duration of the research.

From the initial findings, a noticeable improvement in pass rate was observed for students who attended the practical sessions compared with those who did not. This can be regarded as an incentive to make the mine surveying practicals compulsory in future while integrating them with the current learning and assessment. One consequence of this would be the training of well-rounded technicians with sought-after skills for the South African mining industry.

\section{Keywords}

mine surveying, open distance learning, on-campus practicals, mining engineering education. is initially aimed at supplementing students' formal training with relevant mine surveying exercises.

In order to assess the impact of the programme, historical data pertaining to the performance of students over the last five years was extracted from the University database. Six mine surveying modules forming part of the National Diploma in Mining Engineering and National Diploma in Mine Surveying offered at UNISA were considered. Mine surveying subjects include Mine Survey II and III and Mine Valuation II and III; while mining engineering subjects include Mine Survey and Valuation II and III. A roster was designed for mine surveying practicals for implementation over one year, with students' attendance being optional. The students who accepted the invitation were monitored for the duration of the research. Statistical analysis centred on the hypothesis was performed to determine the change in status before and after the inception of the programme. Finally, recommendations for future work are proposed and conceivable changes to tuition policies evoked.

\section{The National Diploma in Mining Engineering and Mine Surveying}

The National Diploma in Mining Engineering and in Mine Surveying are two of the formal engineering qualifications offered by UNISA's Department of Electrical and Mining Engineering, which is based on the Science Campus in Florida, Roodepoort. The Department of Electrical and Mining Engineering forms part of the School of Engineering, which itself forms part of the College of Science, Engineering and Technology (CSET), as shown in Figure 1.

* Department of Electrical and Mining Engineering, Univerity of South Africa, Science Campus, South Africa.

(C) The Southern African Institute of Mining and Metallurgy, 2017. ISSN 2225-6253. Paper received Jul. 2016; revised paper received Feb. 2017. 


\section{On-campus mine surveying practicals}

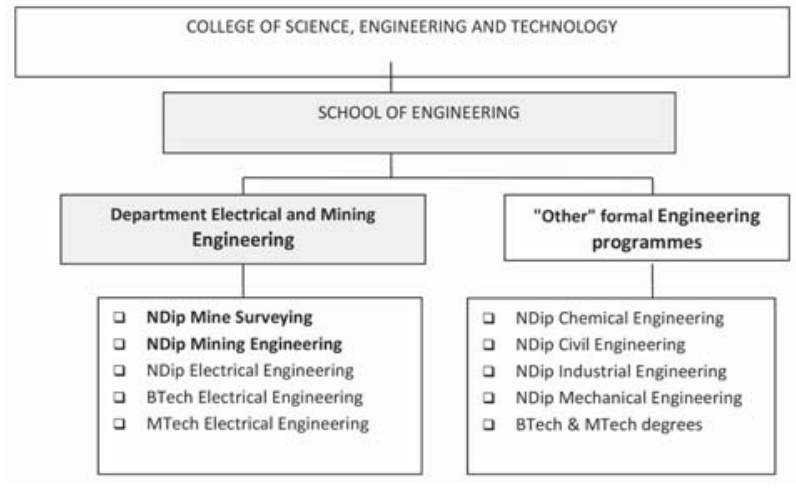

Figure 1-Engineering qualifications offered by CSET at UNISA (source: Self-Evaluation Report-National Diploma in Mine Surveying, internal unpublished document)

\section{The National Diploma in Mining Engineering}

The purpose of this qualification is to produce competent mining technicians whose responsibilities would include the selection and managing of the optimal mining process for the mineral deposit in question. A qualified person with sufficient experience will be able to register with the Engineering Council of South Africa (ECSA) as a Professional Technician in this field of engineering. This programme is a prerequisite for the BTech Mining Engineering offered by the University of Johannesburg.

The NDip Mining Engineering programme helps candidates to obtain a Mine Manager's Certificate of Competency (MMCoC) since it covers the syllabus of Part A as well as sections of Part B. Students who completed the diploma may apply to the Department of Mineral Resources (DMR) for exemption from Part A of the MMCoC.

The curriculum of the programme is presented in Table I.

\section{The National Diploma in Mine Surveying}

The main purpose of the National Diploma in Mine Surveying is to produce competent mine surveyors whose responsibilities would include taking measurements on and under the surface of the earth in a horizontal and vertical plane, showing the results in the form of a map, plan, or 3D computer model after certain calculations have been done.

Many previously disadvantaged students are enrolled for mining programmes at UNISA. Statistics collected from the Institutional Information Portal (Directorate: Information and Analysis, 'HEDA' (Unisa, 2016a)) reveal that they represent about $95 \%$ of all mining-related students over the last five years. UNISA thereby assists mining companies to meet the requirements of the Mining Charter. Health and safety in the minerals industry continues to be a priority. UNISA wants to better equip future graduates with regard to mine health and safety in particular.

The curriculum of the National Diploma in Mine Surveying is outlined in Table II. It is important to point out that UNISA and the University of Johannesburg are the only two universities in South Africa offering a diploma in mine/minerals surveying. UNISA is the only university that offers such a programme by distance learning.

\section{$O D L$ context of learning}

Methodologies used in distance learning differ from those used in residential universities. In ODL, students are issued with a study package upon registration, consisting of study guides, tutorial letters, and course notes. Textbooks are prescribed where course notes are not provided by UNISA. The assignments are included in tutorial letters. Students do not attend classes, but limited discussion classes and lecture consultation sessions are offered in some cases. Discussion classes are not compulsory and are not offered to remote students in South Africa, Africa, and the rest of the world. To compensate for this, UNISA uses e-learning technologies to a large extent. The UNISA learning management system (LMS), called myUnisa, is the UNISA online student portal and the university's most important study tool (UNISA, 2016b). Students can download all course material, as well as additional resources. myUnisa is also called the "virtual campus for distant learners'. It constitutes a platform where students can interact with fellow students, lecturers, and tutors.

Through self-study the students work through the study guides in their own time, complete the assignments (two or three), and submit them for assessment. Tutorial letters are used by lecturers to provide feedback on assignments and to discuss general problems regarding the subject content. Some lecturers provide such feedback individually when they mark student assignments. Lecturers, and in some cases also tutors, are appointed for each subject to offer academic support to the students via telephone, e-mail, MyUnisa (internet), and personal sessions where required.

A year mark is calculated from assignment marks. The year mark has a weight of $20 \%$ when the final mark is calculated; the examination (summative assessment) has a weight of $80 \%$. There are three examination periods, namely January/February, May/June, and October/November. All semester modules have examinations in May/June and October/November respectively for students registered in semester 1 or semester 2. Examinations for full-year modules are held in October/November, and in January/February of the following year for students who qualified to write a supplementary examination (i.e. students who have failed with a minimum of $40 \%$ ). The supplementary examination for semester modules is granted on the same condition but is written in the following session of examination.

At a residential institution a student will typically register for all level 1 subjects in a semester. At UNISA a student may register for subjects from levels 1,2 , and 3 simultaneously provided that the prerequisites are fulfilled. As indicated in Tables I and II, nearly all subjects/modules are offered over a period of a semester, while a few are offered over a full year. The remaining full-year modules are in the process of being semesterized. Certain subjects, for example work integratedlearning (WIL) subjects, remain full-year subjects.

The experiential learning components of the programmes, also called work-integrated learning (WIL) are divided into separate modules covering the required levels of the programmes as shown in Tables I and II. These subjects are administered as individual modules. UNISA staff monitor the experiential learning of students continuously through feedback from students and mentors, completion of assignments and logbooks, and visits to the workplace where possible. 


\section{On-campus mine surveying practicals}

Table I

Curriculum of the National Diploma in Mining Engineering

National Diploma: Mining Engineering

\begin{tabular}{l|l} 
Qualification code: NDMIN & NQF Exit level: 6
\end{tabular}

Total credits: $\mathbf{3 6 0}$

Admission requirements: A National Senior Certificate (Diploma endorsement) with at least $50 \%$ in the language of teaching and learning and with at least $50 \%$ in Mathematics and Physical Science. Students who do not meet the additional requirements may follow Unisa's alternative pathway.

Purpose statement: To produce competent mining engineers whose responsibilities would include the selection and managing of the optimal mining process applicable to the relevant mineral deposit to be mined. A qualified person with sufficient experience will be able to register with the Engineering Council of South Africa (ECSA) as a Professional Technician in this field of Engineering.

\begin{tabular}{|c|c|c|c|}
\hline Module Code & Module name & Prerequisite/Co-requisite & Semester/Year \\
\hline \multicolumn{4}{|c|}{ First level: Group A. Compulsory } \\
\hline ENN103F & English for Academic Purposes & & Semester \\
\hline EUP1501 & $\begin{array}{l}\text { Ethical Information and Communication } \\
\text { Technologies for Development Solutions }\end{array}$ & & Semester \\
\hline MAT1581 & Mathematics I (Engineering) & & Semester \\
\hline MEP171X & Mineral Exploitation I & & Semester \\
\hline SMI181Q & Science: Mining I & & Semester \\
\hline STA1510 & Basic Statistics & & Semester \\
\hline \multicolumn{4}{|c|}{ Second level: Group A. Compulsory } \\
\hline CAD161S & Computer Aided Draughting I & Co-requisite: MED161Q & Semester \\
\hline ENV301E & Environmental Management & & Semester \\
\hline EWS121Q & Engineering Work Study I & & Semester \\
\hline FAC1501 & Introductory Financial Accounting & & Semester \\
\hline MAT2691 & Mathematics II (Engineering) & Prerequisite: MAT1581 & Semester \\
\hline MED161Q & Mechanical Engineering Drawing I & & \\
\hline MPR101E & Mining Engineering Practice I & & Year (WIL) \\
\hline MPR201E & Mining Engineering Practice II & & Year (WIL) \\
\hline \multicolumn{4}{|c|}{ Third level: Group A. Compulsory } \\
\hline EMA2601 & Engineering Management II (Module A) & & Semester \\
\hline EMA2602 & Engineering Management II (Module B) & & Semester \\
\hline MBE2601 & Mineral Beneficiation II & Prerequisite: MEP171X & Semester \\
\hline MEN2601 & Mine Engineering II & Prerequisite: SMI181Q & Semester \\
\hline MGY2601 & Mining Geology II & Prerequisite: MEP171X & Semester \\
\hline MIN2601 & Mining II & Prerequisite: MEP171X & Semester \\
\hline SAV2601 & Mine Survey and Valuation II & Prerequisite: MEP171X & Semester \\
\hline \multicolumn{4}{|c|}{ Fourth level Group A. Compulsory } \\
\hline EMA3601 & Engineering Management III & $\begin{array}{c}\text { Prerequisite: EMA2601 or } \\
\text { EMA2M1E \& EMA2602 or } \\
\text { EMA2M2E }\end{array}$ & Semester \\
\hline GMI3601 & Geology: Mining III & Prerequisite: MGY2601 or MGY291S & Semester \\
\hline MIE3601 & Mine Engineering III & Prerequisite: MEN2601 or MEN251W & Semester \\
\hline MIN3601 & Mining III & Prerequisite: MIN2601 or MIN201E & Semester \\
\hline MTS351X & Mining Technical Services III & Prerequisite: MEP171X & Semester \\
\hline SAV3601 & Mine Survey and Valuation III & Prerequisite: SAV2601 or SAV231Y & Semester \\
\hline
\end{tabular}

\section{The need for mine surveying practical sessions on campus}

Mine surveying practicals on campus were developed to support the theoretical study of mine surveying subjects, since these subjects have been found to be challenging to the majority of students. This is particularly true of private students, since they have never had the opportunity to visit or undergo training in a mine survey department.

Table III shows the pass rates and the number of students enrolled in 2012, indicating the difference between private and professional students. The challenge faced by private students transpires through their poor performance compared with professional students. For 2012 used as baseline, the average pass rate of private students is only $10 \%$, against $26 \%$ for professional students.

\section{Data collection}

In this section, the structure of the programme for on-campus practicals is presented. Student performance is also reviewed in order to form a baseline for comparison before and after implementation of the on-campus programme.

\section{Structure of on-campus practicals}

Mine surveying practicals were implemented from 22 February 2016 on the Science Campus of UNISA. The Mining Engineering laboratory and the vicinity of the campus were 


\section{On-campus mine surveying practicals}

\begin{tabular}{|c|c|c|c|}
\hline Curriculum of the $\mathrm{Na}$ & Diploma in Mine Surveying & & \\
\hline National Diploma: Mine Surv & & & \\
\hline Qualification code: NDMSR & NQF Exit level: 6 & Total credits: 360 & \\
\hline $\begin{array}{l}\text { Admission requirements: A N } \\
50 \% \text { in Mathematics and Phy }\end{array}$ & $\begin{array}{l}\text { enior Certificate (Diploma endorsement) wit } \\
\text { ence. Students who do not meet the additio }\end{array}$ & $\begin{array}{l}0 \% \text { in the language of teaching and learn } \\
\text { ents may follow Unisa's alternative path }\end{array}$ & with at least \\
\hline $\begin{array}{l}\text { Purpose statement: To produ } \\
\text { of the earth either in a horizor }\end{array}$ & $\begin{array}{l}\text { etent mine surveyors whose responsibilities } \\
\text { rtical plane and showing the results in the fo }\end{array}$ & $\begin{array}{l}\text { would include taking measurements upc } \\
\text { p or plan applicable to the relevant miner }\end{array}$ & $\begin{array}{l}\text { under the surface } \\
\text { sit to be mined. }\end{array}$ \\
\hline First level: Group A. Compt & & & \\
\hline ENN103F & English for Academic Purposes & & Semester \\
\hline MAT1581 & Mathematics I (Engineering) & & Semester \\
\hline MEP171X & Mineral Exploitation I & & Semester \\
\hline MSP101R & Mine Survey Practice I & & Year (WIL) \\
\hline SMI181Q & Science: Mining I & & Semester \\
\hline STA1510 & Basic Statistics & & Semester \\
\hline Second level: Group A. Cor & & & \\
\hline EMA2601 & Engineering Management II (Module A) & & Semester \\
\hline EMA2602 & Engineering Management II (Module B) & & Semester \\
\hline EUC1501 & End-User Computing I (Theory) & & Semester \\
\hline EUP1501 & $\begin{array}{l}\text { Ethical Information and Communication } \\
\text { Technologies for Development Solutions }\end{array}$ & & Semester \\
\hline MAT2691 & Mathematics II (Engineering) & Prerequisite: MAT1581 & Semester \\
\hline MGY2601 & Mining Geology II & Prerequisite: MEP171X & Semester \\
\hline MSG211Q & Mine Survey II & Prerequisite: MEP171X & Semester \\
\hline MSP242S & Mine Survey Practice II & & Year (WIL) \\
\hline MVA231Q & Mine Valuation II & Prerequisite: MEP171X & Semester \\
\hline Third level: Group A. Comp & & & \\
\hline EMA3601 & Engineering Management III & $\begin{array}{c}\text { Prerequisite: EMA2601 or } \\
\text { EMA2M1E \& EMA2602 or EMA2M2E }\end{array}$ & Semester \\
\hline MSG3601 & Mine Survey III & Prerequisite: MSG211Q & Year \\
\hline MSP352T & Mine Survey Practice III & & Year (WIL) \\
\hline MVA3601 & Mine Valuation III & Prerequisite: MVA231Q \& STA1510 & Year \\
\hline STG381S & Structural Geology III & Prerequisite: MGY291S & Year \\
\hline
\end{tabular}

Table III

Number of students enrolled in 2012 and their pass rate per subject and category

\begin{tabular}{|c|c|c|c|c|c|c|}
\hline & \multicolumn{3}{|c|}{ Number of students enrolled in 2012} & \multicolumn{3}{|c|}{ Pass rates per subject/category } \\
\hline & Private & Professional & Total & Private & Professional & Total \\
\hline $\begin{array}{l}\text { Mine Survey II } \\
\text { Mine Valuation II } \\
\text { Mine Survey III } \\
\text { Mine Valuation III } \\
\text { Mine Survey and Valuation II } \\
\text { Mine Survey and Valuation III }\end{array}$ & $\begin{array}{l}45 \\
68 \\
18 \\
10 \\
90 \\
38\end{array}$ & $\begin{array}{l}12 \\
19 \\
12 \\
14 \\
39 \\
58\end{array}$ & $\begin{array}{c}57 \\
87 \\
30 \\
24 \\
129 \\
96\end{array}$ & $\begin{array}{c}12 \% \\
13 \% \\
27 \% \\
13 \% \\
2 \% \\
15 \%\end{array}$ & $\begin{array}{c}26 \% \\
21 \% \\
47 \% \\
21 \% \\
6 \% \\
38 \%\end{array}$ & $\begin{array}{c}39 \% \\
33 \% \\
73 \% \\
33 \% \\
8 \% \\
56 \%\end{array}$ \\
\hline
\end{tabular}

used for this purpose. Student attendance was optional. The practical sessions were run on a weekly basis from Monday to Friday. The students who accepted the invitation to be part of the programme were received on a 'first-come first-served' basis in a group of 5 to 6 per session.

The first week of the practical sessions was devoted to traversing. The following week, students were exposed to levelling and grading techniques. This sequence was repeated alternately to accommodate all the students booked for training.

\section{Performance of students}

A study conducted at the University of the Witwatersrand developed methodologies for assessing the effectiveness of supplemental instruction (SI). The method involves various kinds of comparison between students who have attended a given number (or more) of SI sessions and those who have attended fewer than this number, or no sessions at all ((Martin et al., 1992; Bidgood, 1992; Congos and Schoeps, 1993), cited by McCarthy, et al., 1997). Practicals on campus can be assimilated to supplemental instruction. Therefore the same methodology is used in this paper for comparing the performances of two groups of students.

The key metric used to quantify students' performance is the pass rate calculated after each examination period (January/February, May/June, and October/November). For 


\section{On-campus mine surveying practicals}

simplicity, these periods are labelled as January, June, and October respectively. The official examination results are kept in the database of the academic department for each subject. These are filed as historical data for auditing purpose and statistical analysis. They can also be obtained on request from the Examination Administration Division. These two sources of information were used and consulted to compile the pass rates over five years (2011 to 2015) for six mine surveying modules forming part of the National Diploma in Mining Engineering and National Diploma in Mine Surveying offered at UNISA during the period under consideration: Mine Survey II and III, Mine Valuation II and III, and Mine Survey and Valuation II and III.

Mine Survey II and Mine Valuation II were offered during the period under investigation as semester modules with two sitting examinations June and October. Mine Survey and Valuation II and III were offered as full-year modules until 2013, with one examination in October followed by a supplementary in January. Therefore, the results for the January session are combined with those of the October session from the previous year to obtain the overall results for each year. However, these modules were 'semesterized' from 2014 and now have two examination sittings - one in June and one in October. For semester modules, the June and October results are combined to reflect the results for each year. Students who fail in June and qualify for supplementary examination re-write in October of the same year, or in general during the next semester session of examination.

The principle of combining October and January results applies also to Mine Survey III and Mine Valuation III, which were full-year modules during the entire period of investigation.

The pass rate is calculated as the number of students who passed as a percentage of the number of students who wrote the examination in each period. However, it should be noted that all students admitted for examination do not necessarily write, due to the drop-out rate.

The full names of modules are presented in Tables I and II. However, for the analysis of the results, each subject is further described by its code as listed in Table IV.

\section{Student attendance at mine survey practicals}

A roster was designed for mine surveying practicals for implementation over a year, split in the two semesters. Students had the choice to opt into two of the six sessions scheduled per semester on the roster, shown in Table V. Three groups were formed; labelled A, B, and C.
Students' attendance at practicals was recorded and is summarized in Table VI.

It appears that the attendance was very low, at $6 \%$, for the first semester. This can be explained in part by the fact that the practicals were optional. The attendees were monitored for the duration of this research. It will be shown later, when discussing the results, that not all students registered were admitted to sitting for the May/June examination period. Some of students cancelled their registration for financial reasons, which is one of the causes of drop-out. Some did not meet the minimum requirement of submitting at least one assignment in order to gain access to examination.

\section{Results and findings}

As stated prior to the analysis, the average pass rate for all the subjects over the last five years is very low (28\%), and varies significantly from one year to another as well between

Table IV

Mine surveying modules offered in the two qualifications NDMIN and NDMSR

\begin{tabular}{|l|c|}
\hline Subjects & Module codes \\
\hline Mine Survey II & MSG211Q \\
Mine Valuation II & MVA231Q \\
Mine Survey and Valuation II & SAV2601 \\
Mine Survey III & MSG3601 \\
Mine Valuation III & MVA3601 \\
Mine Survey and Valuation III & SAV3601 \\
\hline
\end{tabular}

Table $\mathrm{V}$

Roster of survey practicals

\begin{tabular}{|l|c|c|c|}
\hline \multicolumn{4}{|c|}{ Semester 1 } \\
\hline & Group A & Group B & Group C \\
\hline $\begin{array}{l}\text { Traversing } \\
\text { Levelling /grading }\end{array}$ & $22 / 02-26 / 02$ & $07 / 03-11 / 03$ & $04 / 04-08 / 04$ \\
$29 / 02-04 / 03$ & $14 / 03-18 / 03$ & $11 / 04-15 / 04$ \\
\hline \multicolumn{4}{|c|}{ Semester 2 } \\
\hline Traversing & $18 / 07-22 / 07$ & $15 / 08-19 / 08$ & $29 / 08-02 / 09$ \\
Levelling /grading & $25 / 07-29 / 07$ & $22 / 08-26 / 08$ & $05 / 09-09 / 09$ \\
\hline
\end{tabular}

Table VI

Number of students who attended practicals vs number of students enrolled in 2016

\begin{tabular}{|c|c|c|c|}
\hline & Number of students enrolled in 2016 (Semester 1 and year) & Number of students attended practicals & Attendance (\%) \\
\hline Mine Survey II & 61 & 7 & $11 \%$ \\
\hline Mine Valuation II & 40 & 2 & $5 \%$ \\
\hline Mine Survey III & 29 & 2 & $7 \%$ \\
\hline Mine Valuation III & 27 & 1 & $4 \%$ \\
\hline Mine Survey and Valuation II & 170 & 13 & $8 \%$ \\
\hline Mine Survey and Valuation III & 163 & 6 & $4 \%$ \\
\hline Total & 490 & 31 & $6 \%$ \\
\hline
\end{tabular}




\section{On-campus mine surveying practicals}

the different modules. The low pass rate can be attributed to the lack of practical experience among students enrolling directly from high school.

Figure 2 shows the pass rates for all the modules from 2011 to 2015.

In order to assess the trend in pass rates over the period under investigation, separate charts with trend-lines are provided for each module in Figures 3 and 4. Similar trends can be observed for the other mine surveying modules as shown in Figure 2.

It can be noted that the pass rate is decreasing for all the modules except for MVA3601. This is alarming and indicates the need to find solutions that can help to improve the situation.

The pass rates for all the modules over five years from 2011 to 2015 are summarized in Table VII.

The number of students enrolled in 2016 was reported in Table VI. As stated previously, not all students who registered wrote in the June examination period, which will be used to assess the impact of practicals on the results of semester's mine survey modules MSG211Q, MVA231Q, SAV2601, and SAV3601. Table VIII shows the number of students who wrote in the June examination period and therefore indicates the number of students who dropped out for any of the reasons mentioned.

The ratio of students writing the examination to those enrolled is $82 \%$, indicating a significant rate of absence $(18 \%)$ at the examination. Dropping out remains a serious concern for engineering studies. A study conducted at the Faculty of Engineering of the University of KwaZulu-Natal reports a similar academic drop-out rate of 14\% (Pocock,

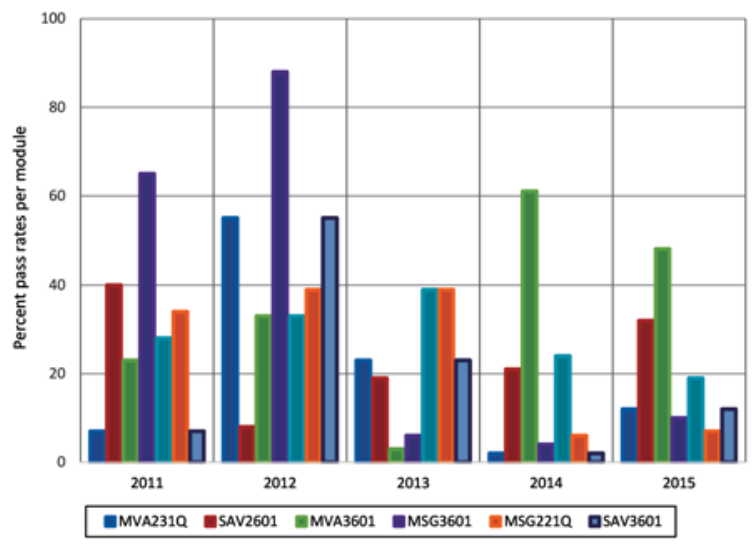

Figure 2-Historical records of pass rates per mine surveying module over the period 2011-2015 at UNISA
2012). An analysis of, and interviews with, a sample of the students who left showed that financial reasons played a significant role, with $49 \%$ of non-academically excluded students having financial difficulties, and that a significant proportion of students continue their studies at universities of technology.

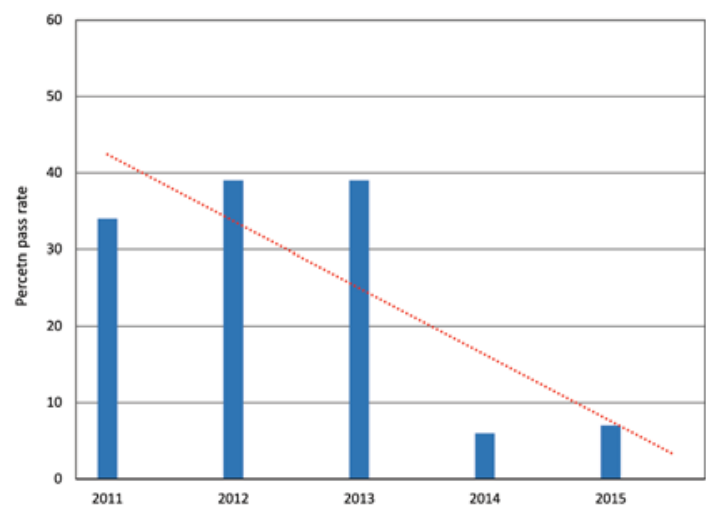

Figure 3-Percentage pass rates for Mine Survey II (MSG211Q)

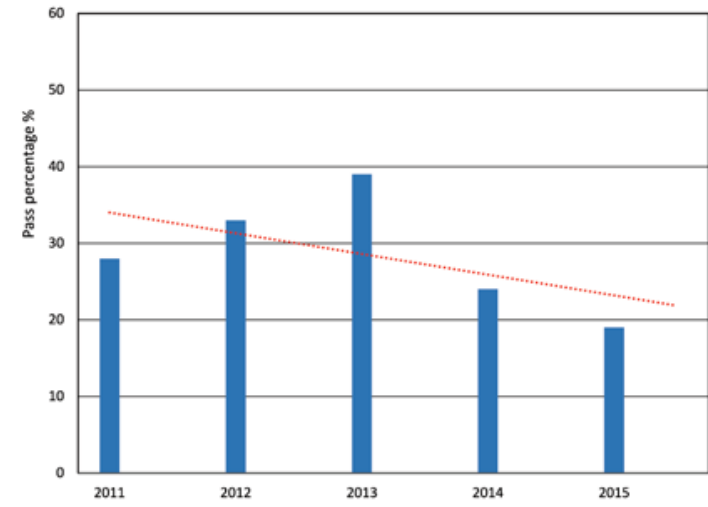

Figure 4-Percentage pass rates for Mine Valuation II (MVA231Q)

Table VII

Pass rates per module per year $(\%)$

\begin{tabular}{|l|c|c|c|c|c|}
\hline & $\mathbf{2 0 1 1}$ & $\mathbf{2 0 1 2}$ & $\mathbf{2 0 1 3}$ & $\mathbf{2 0 1 4}$ & $\mathbf{2 0 1 5}$ \\
\hline Mine Survey II & $\mathbf{3 4}$ & $\mathbf{3 9}$ & $\mathbf{3 9}$ & 6 & 7 \\
Mine Valuation II & 28 & 33 & 39 & 24 & 19 \\
Mine Survey III & 65 & $\mathbf{7 3}$ & 6 & 4 & 10 \\
Mine Valuation III & 23 & 33 & 3 & 61 & 48 \\
Mine Survey and Valuation II & 40 & 8 & 19 & 21 & 32 \\
Mine Survey and Valuation III & 7 & 55 & 23 & 2 & 12 \\
\hline
\end{tabular}

Table VIII

Number of students writing examinations vs number enrolled and drop-outs

\begin{tabular}{|c|c|c|c|c|}
\hline & $\begin{array}{l}\text { Number of students enrolled in } \\
22016 \text { (S1) }\end{array}$ & $\begin{array}{l}\text { Number of students written in } \\
\qquad 2016 \text { (S1) }\end{array}$ & $\begin{array}{l}\text { Number of students absent } \\
\text { (not admitted and drop-outs) }\end{array}$ & $\begin{array}{l}\text { Students writing } \\
\text { examination (\%) }\end{array}$ \\
\hline $\begin{array}{l}\text { Mine Survey II } \\
\text { Mine Valuation II } \\
\text { Mine Survey and Valuation II } \\
\text { Mine Survey and Valuation III } \\
\text { Total }\end{array}$ & $\begin{array}{c}61 \\
40 \\
170 \\
163 \\
434\end{array}$ & $\begin{array}{c}50 \\
31 \\
145 \\
128 \\
354\end{array}$ & $\begin{array}{c}11 \\
9 \\
25 \\
35 \\
80\end{array}$ & $\begin{array}{l}82 \% \\
78 \% \\
85 \% \\
79 \% \\
82 \%\end{array}$ \\
\hline
\end{tabular}




\section{On-campus mine surveying practicals}

After the inception of the practicals, it was noted that a low proportion of students attended compared to the total number of students enrolled for the year and the first semester. From Table VI, a total of 31 students, representing $6 \%$ of the total enrolled, attended. A further investigation shows that out the 31 students, only 19 students wrote the June examination, which represents $5 \%$ of the cohort examined, as illustrated in Table IX.

To assess the impact of practicals, the pass rates of students who attended are compared to those who did not attend. The average pass rate of students who attended is $46 \%$, while it is $39 \%$ for the other group. A single factor analysis of variance (ANOVA) was performed using Microsoft Excel to test the hypothesis that the means of the two groups are equal. The result of the test is summarized in Table X.

The terms from Table $\mathrm{X}$ have the following meanings in the test as performed using the data analysis tool in Excel: SS = Sum of Squares, $\mathrm{df}=$ Degree of freedom, MS = Mean square, $\mathrm{F}=$ Test statistic, and $\mathrm{F}$ crit = the critical value of the test. In concluding the test, $\mathrm{F}<\mathrm{F}$ crit means that we fail to reject the hypothesis that the two means are equal. In other words, the sample evidence is not strong enough to warrant rejection of the null hypothesis.

The individual pass rates for the modules written in the June examination are shown in Table XI. A noticeable improvement is evident compared to the previous examination period.

\section{Discussion}

The improved pass rate among students who attended the practical sessions can be regarded as an incentive to make the mine surveying practicals compulsory in future while integrating them to the current learning and assessment.

Is the overall and partial pass rate increase compared to five previous years attributable to practicals? Considering the amount of information available at this stage, it would be premature to give a definite answer. Therefore it is recommended that the scope of the investigation be extended beyond one year and to cover various cohorts of students.

\section{Conclusions}

The results of this study constitute an incentive to make the mine surveying practicals compulsory in future while integrating them with the current learning and assessment. One consequence of this would be the training of wellrounded technicians with sought-after skills for the South African mining industry.

\section{Table XI}

Comparison of pass rates in June examination to the previous sessions

\begin{tabular}{|l|c|c|}
\hline \multirow{2}{*}{} & \multicolumn{2}{|c|}{ Pass rates } \\
\cline { 2 - 3 } & 2011-2015 & 2016 (S1) \\
\hline Mine Survey II & 24 & 26 \\
Mine Valuation II & 29 & 68 \\
Mine Survey and Valuation II & 25 & 50 \\
Mine Survey and Valuation III & 20 & 22 \\
Average & 25 & 36 \\
\hline
\end{tabular}

Table IX

Summary of the results per module

\begin{tabular}{|c|c|c|c|c|c|}
\hline & $\begin{array}{l}\text { Number of students examined } \\
22016 \text { (S1) }\end{array}$ & $\begin{array}{l}\text { Number of students } \\
\text { attended practicals }\end{array}$ & $\begin{array}{c}\text { Attendance } \\
(\%)\end{array}$ & $\begin{array}{c}\text { Examination pass } \\
\text { rate }\end{array}$ & $\begin{array}{c}\text { Relative pass rate } \\
\text { increase }\end{array}$ \\
\hline $\begin{array}{l}\text { Mine Survey II } \\
\text { Mine Valuation II } \\
\text { Mine Survey and Valuation II } \\
\text { Mine Survey and Valuation III } \\
\text { Total }\end{array}$ & $\begin{array}{c}50 \\
31 \\
145 \\
128 \\
354\end{array}$ & $\begin{array}{c}4 \\
0 \\
10 \\
5 \\
19\end{array}$ & $\begin{array}{l}8 \% \\
0 \% \\
7 \% \\
4 \% \\
5 \%\end{array}$ & $\begin{array}{l}26 \% \\
68 \% \\
50 \% \\
22 \% \\
36 \%\end{array}$ & $\begin{array}{c}8 \% \\
134 \% \\
100 \% \\
10 \% \\
44 \%\end{array}$ \\
\hline
\end{tabular}

Table $X$

\section{Analysis of variance}

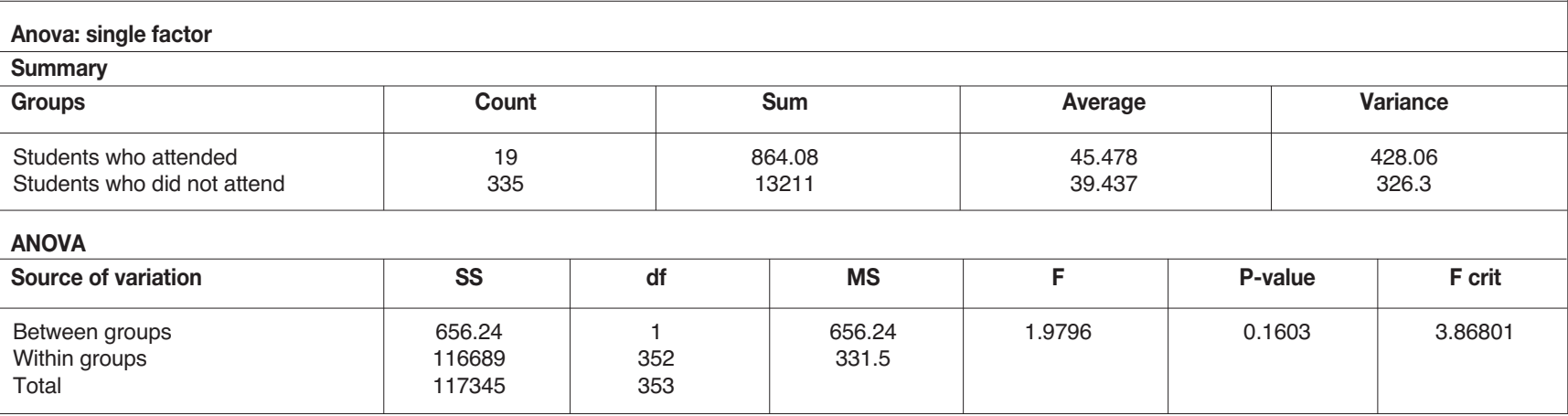




\section{On-campus mine surveying practicals}

The findings in this paper are limited to UNISA. However, it would be interesting to investigate and compare the performance of students in surveying disciplines at other institutions in South Africa and internationally. In this regards, attempts were made to collect statistical information from neighbouring institutions (in South Africa), but data could be not be obtained before this paper was submitted for publication. The same challenge may arise when dealing with institutions abroad.

In the opinion of the author, a more detailed paper can presented in the future that can shed light on what is happening elsewhere with teaching and learning of geomatics.

\section{Acknowledgements}

The author would like to thank the Examination Department of the University of South Africa for providing the statistics used in this work.

Special thanks to the Department of Electrical and Mining Engineering for support throughout the execution of the research work.

\section{References}

McCARThy, A., Smuts, B., and Cosser, M. 1997. Assessing the effectiveness of supplemental instruction: A critique and a case study. Studies in Higher Education 22, no. 2: 221-31.

Pocock, J. 2012. Leaving rates and reasons for leaving in an engineering faculty in South Africa: A case study. South African Journal of Science, vol. 108, no. 3-4. pp. 60-67.

TriolA, M.F. 2005. Essentials of Statistics. Pearson Addison Wesley, Boston, MA

UNISA. 2016a. Directorate: Information and Analysis (DIA), Information and Institutional Analysis Portal, Unisa, http://heda.unisa.ac.za/indicatordashboard/default.aspx [Accessed 5 July 2016]

UNISA. 2016b. Learning Management System (LMS)myUnisa,http://www.unisa.ac.za/sites/default/

UNISA. 2016c. MyRegistration@Unisa. College of Science, Engineering and Technology (online brochure). https://registration.unisa.ac.za/info/ [Accessed 25 April 2016].

UNISA. 2016d. XMO - examination marks online. (Intranet). http://www2.unisa.ac.za/AOL/XMO/

UNISA. 2014. Self-evaluation portfolio: National Diploma in Mine Surveying, 2014 (unpublished). 